Review Article

\title{
Expansion Mechanism and Properties of Magnesium Oxide Expansive Hydraulic Cement for Engineering Applications
}

\author{
Siqi Li $\mathbb{D}$, Yecheng Feng $(\mathbb{D}$, and Jinbo Yang $\mathbb{1}$ \\ School of Civil Engineering, College of Water Conservancy and Civil Engineering, Shandong Agricultural University, \\ Taian 271018, Shandong, China
}

Correspondence should be addressed to Jinbo Yang; yangjinbo@tsinghua.org.cn

Received 4 February 2021; Revised 5 April 2021; Accepted 26 April 2021; Published 5 May 2021

Academic Editor: Robert Cerny

Copyright (C) 2021 Siqi Li et al. This is an open access article distributed under the Creative Commons Attribution License, which permits unrestricted use, distribution, and reproduction in any medium, provided the original work is properly cited.

The expansion mechanism of magnesium oxide expansive hydraulic cement as a novel expansive hydraulic cement was reviewed. Anisotropic crystallization results in crystal growth pressure, causing volume expansion while also increasing the porosity of the whole system. The theoretical relationship between porosity and expansion was analyzed. A basic method is given for predicting the expansion rate considering the expansive agent content in $\mathrm{MgO}$ expansive hydraulic cement. A concise equation is proposed for calculating the ultimate expansion. A theoretical relationship between porosity and expansion is presented. The compressive strength and durability of magnesium oxide expansive hydraulic cement were analyzed considering porosity changes and compared with hydraulic cement. If the expansion rate exceeds $0.8 \%$, the mechanical properties and durability changes caused by porosity should be considered. If magnesium oxide expansive concrete is used with restraining in real structure, extra compressive stress is generated and the porosity decreases, compared with that during free expansion. In particular, for strain-hardening cementitious composites, expansion confined with the fibers present in the composite is beneficial for refining cracks and improving the self-healing ability of these materials whenever exposed to humid environments. This paper describes the expansion mechanism and properties of magnesium oxide expansive hydraulic cement for engineering applications.

\section{Introduction}

The elimination of cracks in hydraulic cement concrete structures is a global issue; eliminating cracks is necessary for improving the durability of these structures and saving maintenance and repair costs. Hydraulic cement commonly refers to Portland cement and slag cement; it has an extremely wide range of applications throughout the world and is expected to be used extensively in future as well. This cement sets and hardens via chemical reactions with water and is capable of doing so underwater. Concrete containing hydraulic cement has a minor underwater volume expansion. However, when exposed to atmospheric conditions and restrained internally or externally, it always produces cracks caused by thermal contraction or drying shrinkage; these cracks might cause problems in terms of the structural stability and durability at different levels [1]. Thermal contraction and drying shrinkage resulting from hydration and water evaporation (or consuming) are hardly eliminated as concrete contains water.

To maintain the volume stability of concrete or reduce drying shrinkage (or thermal contraction), expansive hydraulic cement containing expansive agents or an expansive component was studied and utilized over the past half-century; in particular, shrinkage-compensating concrete is used worldwide [2-10]. The three common expansive portions in expansive hydraulic cement are based on calcium sulfoaluminate $\left(4 \mathrm{CaO} \cdot 3 \mathrm{Al}_{2} \mathrm{O}_{3} \cdot \mathrm{SO}_{3}\right)$, calcium oxide $(\mathrm{CaO})$, and magnesium oxide $(\mathrm{MgO})$. Calcium sulfoaluminate expansive hydraulic cement has been studied since many years $[3,11-14]$. Yan et al. $[15,16]$ found that the shrinkagecompensating effect of calcium sulfoaluminate when used in massive concrete structures cannot be completely utilized when the curing temperature is higher than $70^{\circ} \mathrm{C}$ because of the decomposition of ettringite, which is the main hydration product of calcium sulfoaluminate expansive agents. 
Compared with $\mathrm{CaO}$ expansive agents, $\mathrm{MgO}$ expansive agents have a significant advantage owing to their designable expansion properties [17] because the hydration rate of $\mathrm{MgO}$ is relatively easier to control by controlling different calcination conditions during the manufacturing process. Since the 1970s, $\mathrm{MgO}$ is being used as an expansive agent to compensate for the thermal contraction of mass concrete, particularly in dam concrete used in China; it is extensively used both in research activities and industrial applications [17-19]. Moreover, expansive agents are mineral admixture used for enhancing the performance for self-healing concrete mainly because of their expansion effect [20]. Furthermore, it was proved that the utilization of appropriate dosages of $\mathrm{MgO}$ expansive agents has high potential as a new self-healing method for cracked concrete [21-23]. Moradpour et al. [24] found that adding nano-MgO increased the mechanical strength of cement composites during aging to a certain extent and decreased the permeability of these materials. This is because the microstructures of the cement composites with nano-MgO were more compact and homogeneous than those of normal composites because of expansive effect of nano-MgO.

Therefore, the expansion mechanism and dynamics of $\mathrm{MgO}$ expansive hydraulic cement should be understood thoroughly to determine the optimal dosages of $\mathrm{MgO}$ for use during actual construction and avoid overdose to avoid damages to concrete structures. The mechanism for the expansion of dead-burnt $\mathrm{MgO}$ and $\mathrm{CaO}$ was first studied by Chatterji based on the crystal growth pressure, solubility of hydroxide crystals, their growth patterns, and diffusion of ions through the electrical double layer formed around the cement hydration products $[25,26]$. According to the above mechanism, Mo et al. built an image model of an $\mathrm{MgO}$ expansive agent considering the inner pore structure of the expansive agent but could not simulate the expansive process and expansion mechanism in $\mathrm{MgO}$ expansive agent concrete $[17,27]$. The expansive process and expansion mechanism need to be stated clearly to identify the main design parameters for shrinkage-compensating concrete, which are mainly dependent on the type and content of the expansive agent, the hydraulic cement matrix, and environmental conditions of real concrete structures $[28,29]$. Likewise, the relationship between expansion and mechanical properties and durability should be studied.

This article discusses not only the crystallization pressure theory for explaining the expansion mechanism of $\mathrm{MgO}$ expansive hydraulic cement but also a basic method for predicting the expansion rate considering the expansive agent content in $\mathrm{MgO}$ expansive hydraulic cement. A concise equation is proposed for calculating the ultimate expansion. Autoclave tests are discussed for determining the ultimate expansion. A theoretical relationship between porosity and expansion is presented. Based on this, the connection between expansion, mechanical properties, and durability is discussed. Further studies on concrete under restrained conditions and empirical research will follow.

\section{MgO Expansive Agent}

$\mathrm{MgO}$ expansive hydraulic cement is a mixture of hydraulic cement and $\mathrm{MgO}$ expansive agent, which is responsible for expansion. Mixing of the hydraulic cement and $\mathrm{MgO}$ expansive agent could be carried out during cement manufacture or during concrete mixing. As the $\mathrm{MgO}$ expansive agent is very sensitive to calcination conditions, particularly the calcining temperature, precisely controlling the temperature and residence time and homogeneously heating the magnesite are extremely important for maintaining the quality of $\mathrm{MgO}$ expansive agent [17]. For manufacturing $\mathrm{MgO}$ expansive hydraulic cement or shrinkage-compensating concrete, $\mathrm{MgO}$ expansive agent must be manufactured separately, complying with standards. The first and latest standard for $\mathrm{MgO}$ expansive agent for use in concrete was issued by the China Building Materials Federation and China Concrete and Cement-Based Products Association in 2017 [30]. According to this standard, the product shall conform to the chemical and physical requirements prescribed in Table 1.

\section{Expansion}

3.1. Mechanism of Expansion. Hydration products of $\mathrm{MgO}$ expansive cement include hydration products of hydraulic cement and magnesium hydroxide $\left(\mathrm{Mg}(\mathrm{OH})_{2}\right)$ because the hydration reactions of hydraulic cement and $\mathrm{MgO}$ expansive agent are relatively independent. Hydration of $\mathrm{MgO}$ proceeds according to the following equation, and the volume change is calculated as follows:

$$
\begin{array}{lll}
\mathrm{MgO}+\mathrm{H}_{2} \mathrm{O}=\mathrm{Mg}(\mathrm{OH})_{2}, \\
40.3 \mathrm{~g} & 18.0 \mathrm{~g} & 58.3 \mathrm{~g} \\
11.2 \mathrm{~cm}^{3} & 18.0 \mathrm{~cm}^{3} & 25.3 \mathrm{~cm}^{3}
\end{array} .
$$

The specific gravity values of $\mathrm{MgO}$ and $\mathrm{Mg}(\mathrm{OH})_{2}$ used in the calculation are 3.6 and 2.3. It was found that the system as a whole undergoes a net volume contraction of approximately $13 \%$, and the solid volume increases by approximately $126 \%$. After mixing with water and cement, $\mathrm{MgO}$ particles having micrometer diameters will contact with water and be covered with a water film. When in contact with water, $\mathrm{MgO}$ dissolves in water first. Dissolution of $\mathrm{MgO}$ will increase the concentration of magnesium ions in the water film, and $\mathrm{Mg}(\mathrm{OH})_{2}$ crystals will grow when supersaturation is reached. Neglecting the dissolution of $\mathrm{Mg}(\mathrm{OH})_{2}$, which has a solubility of approximately $0.00064 \mathrm{~g} /$ $100 \mathrm{~mL}\left(25^{\circ} \mathrm{C}\right)$ in water, all $\mathrm{MgO}$ that undergoes hydration to form $\mathrm{Mg}(\mathrm{OH})_{2}$ needs a water-MgO mass ratio more than 0.45 according to equation (1). Crystallization of $\mathrm{Mg}(\mathrm{OH})_{2}$ may occur randomly on the surfaces of $\mathrm{MgO}$ particles, cement particles, or the cement hydration gel. The crystal size of $\mathrm{Mg}(\mathrm{OH})_{2}$ will be in the nanometer range initially and then increases to micrometer levels [6]. If an $\mathrm{Mg}(\mathrm{OH})_{2}$ crystal is confined, the volume increases or crystallization pressure will cause expansion of the hardened cement paste. Steiger [31, 32] provided the following thermodynamically consistent equation for the calculation of the pressure generated during crystal growth in porous materials:

$$
\Delta p_{i}=\frac{\mathrm{RT}}{V_{m}} \ln \frac{a}{a_{\infty}}-\gamma_{c l, i} \frac{\mathrm{d} A_{i}}{\mathrm{~d} V},
$$


TABle 1: Chemical and physical requirements for MgO expansive agent [30].

\begin{tabular}{|c|c|c|c|c|}
\hline \multirow{2}{*}{ Items } & & \multicolumn{3}{|c|}{ Requirements } \\
\hline & & $R$ (rapid type) & $M$ (medium type) & $S$ (slow type) \\
\hline MgO mass content (\%) & $\geq$ & & 80.0 & \\
\hline Loss on ignition (\%) & $\leq$ & & 4.0 & \\
\hline Water content $(\%)$ & $\leq$ & & 0.3 & \\
\hline Reaction time $*(s)$ & & $<100$ & $\geq 100$ and $<200$ & $\geq 200$ and $<300$ \\
\hline \multirow{2}{*}{$\begin{array}{lc}\text { Fineness } & 80 \mu \mathrm{m} \text { square hole sieve residue (\%) } \\
\text { Fm square hole sieve residue (\%) }\end{array}$} & $\leq$ & & 5.0 & \\
\hline & $\leq$ & & 0.5 & \\
\hline
\end{tabular}

Reaction time $*$ is the time required for completing the neutralization reaction between magnesium oxide expansive agent and citric acid solution with definitive concentration

where $\Delta p_{i}$ is the crystal growth pressure at crystal face $i, R$ is the gas constant, $T$ is the absolute temperature, $V_{m}$ is the mole volume of magnesium hydroxide, $a$ is the equilibrium activity of the crystal under pressure $\Delta p_{i}, a_{\infty}$ is the equilibrium activity of the large reference crystal under ambient pressure, $\gamma_{c l, i}$ is the surface-free energy of the crystal-liquid interface at the ith crystal face, and $\mathrm{d} A_{i}$ and $\mathrm{d} V$ are the area of the surface created and the volume transformed during growth at the ith crystal face, respectively. In the limiting case of a very large crystal size greater than approximately $0.1-1 \mu \mathrm{m}$, the interfacial energy term vanishes.

Equation (2) indicates that the crystal growth pressure is the main reason for expansion. Crystallization will occur randomly where the solution is supersaturated; later, as crystal volume increases, the crystal growth pressure increases. According to Steiger's explanation $[31,32]$, a solution film must exist, separating the loaded face of a crystal from its constraint; growth on the loaded face of a crystal can only exert pressure if this face is in contact with a supersaturated solution. The crystal growth pressure theory is effectively utilized to understand the mechanism of expansion, but it is difficult to connect microcosmic crystal properties with macroscopic hardened cement paste or concrete properties directly. Moreover, estimating the degree of supersaturation in pore solutions is apparently unrealistic for calculating crystallization pressures.

Based on crystallization pressure theory, there are three main stages in the hydration of $\mathrm{MgO}$. In the first stage, crystallization occurs when the cement paste or concrete is plastic; in the next stage, crystallization occurs without restraining because the crystal dimensions are relatively small. The above two stages will not cause expansion of the cement system. In the third stage, while the cement paste or concrete is hardened and $\mathrm{Mg}(\mathrm{OH})_{2}$ crystals are restrained, crystallization pressure is caused, leading to expansion.

3.2. Dynamics of Expansion. The hydration dynamics of $\mathrm{MgO}$ in a hydraulic cement system is highly complicated because it is combined with the hydration of cement and influenced by environmental factors such as the pore solution, temperature, and humidity and strongly depends on the concentration of surface defects on $\mathrm{MgO}$ crystals $[17,33,34]$. Different types of $\mathrm{MgO}$, which are calcined at different temperatures, will show different hydration performances with various hydration reactivities. $\mathrm{MgO}$ with high reactivity commonly calcined at approximately $600^{\circ} \mathrm{C}$ undergoes hydration rapidly and thus causes fast expansion at an early age, and the expansion then ceases within a short time approximately $14 \mathrm{~d}$ [17]. According to the experiments of Kasselouris et al. [35], the hydration of periclase, or deadburned $\mathrm{MgO}$, commonly calcined at approximately $1450^{\circ} \mathrm{C}$ with very low reactivity in cement pastes reached a limited value of $73.4 \%$ at a water curing age of about six years. As the pozzolanic activity of the materials with good pozzolanic activity is increased, the hydration of $\mathrm{MgO}$ is reduced. Majumdar and Rehsi [36] stated that the precise mechanism through which the addition of pulverized fly ash or other similar active silica materials reduces the autoclave expansion of Portland cements containing large percentages of $\mathrm{MgO}$ to permissible levels remains unclear. If the hydration environment of $\mathrm{MgO}$ is stable, the expansion should be a continuous process through which expansion will infinitely approach the maximum value assuming that hydration of $\mathrm{MgO}$ will finally reach $100 \%$. Yuan [37] proposed a hyperbolic model for simulating the expansion process for $\mathrm{MgO}$-based expansive hydraulic cement concrete, as shown in the following equation:

$$
\varepsilon_{t}=\frac{t}{\alpha+\left(1 / \varepsilon_{\max }\right) t},
$$

where $\varepsilon_{t}$ is the expansion at time $t, t$ is the time, $\varepsilon_{\max }$ is the ultimate expansion, and $\alpha$ is a factor controlled by the expansive agent type, hydraulic cement matrix, and environment conditions.

In real concrete structures, hydration of reactive magnesium oxide is an infinite process like the hydration of cement. If the ultimate expansion could be determined, expansion of $\mathrm{MgO}$ expansive hydraulic cement concrete can be approximately calculated at any time using equation (3).

3.3. Ultimate Expansion. Expansion of $\mathrm{MgO}$ expansive hydraulic cement is driven by two forces, namely, the crystallization pressure caused by supersaturation and crystallization amount, which are both relative to the expansion agent content according to the above analysis. A possible equation for calculating expansion rate is as follows: 


$$
\varepsilon_{\max }=\beta C^{2},
$$

where $\varepsilon_{\max }$ is the ultimate expansion (\%), $\beta$ is a factor controlled by the expansive agent type and category, hydraulic cement matrix, and environment conditions, and $C$ is the expansion agent content in terms of mass (\%).

Hydration of the $\mathrm{MgO}$ expansive agent will be triggered when it is mixed with water. During the plastic stage of fresh concrete, crystallization will not cause pressure without confinement. This is the reason that $\mathrm{CaO}$ expansive agents have the disadvantages of an extremely fast reaction rate when mixed with water and lower storage stability when exposed to the atmosphere; this reduces its expansion efficiency in shrinkage-compensating concrete [38]. Generally, the ultimate expansion will increase with the increase in expansion agent content. When the ultimate expansion exceeds a particular value or the expansive agent content increases to some value, the whole gel system will disintegrate and lose strength.

3.4. Determining Ultimate Expansion. Hydration of $\mathrm{MgO}$ is a long-term reaction like the hydration of hydraulic cement, making it generally impossible to measure the ultimate expansion. To accelerate the hydration process, extra pressure and high temperature should be applied. Till date, for testing the soundness of hydraulic cement, the autoclave expansion test $\left(216^{\circ} \mathrm{C}, 2 \mathrm{MPa}\right.$, and $\left.3 \mathrm{~h}\right)$ is used to determine the potential delayed expansion caused by the hydration of $\mathrm{CaO}$ or $\mathrm{MgO}$, or both, when present in hydraulic cement $[39,40]$. Owing to potential safety hazards and the fact that not all testing laboratories have access to testing equipment, Michelle [41] found that a very good correlation exists between the standard ASTM $\mathrm{C} 151$ autoclave results and both the 3 -h boiling and $80^{\circ} \mathrm{C}$ $\left(176^{\circ} \mathrm{F}\right)$ water-curing expansion values. However, small expansion values would introduce difficulties in terms of the precision and accuracy of the method and the inherent variability of multiple prisms produced using the same mixture. Although Mo et al. [42] concluded that a curing temperature of $80^{\circ} \mathrm{C}\left(176^{\circ} \mathrm{F}\right)$ was much lower than $216^{\circ} \mathrm{C}\left(420.8^{\circ} \mathrm{F}\right)$, less internal thermal stress may be induced in concrete and no serious destruction of the cement hydration products will be caused; therefore, the test results obtained from this accelerated experiment may be more reliable. Nevertheless, the autoclave expansion test is still the most suitable test for determining the ultimate expansion of $\mathrm{MgO}$ expansive hydraulic cement or concrete according to the experimental results of Gao et al. [43]. According to autoclave test results for cement pastes obtained by Michelle [41] and those for concrete obtained by Gao et al. [43], equation (4) is applied to obtain the relationship between expansion and $\mathrm{MgO}$ content, and the fitted curves are shown in Figure 1 with R-square values of 0.99 and 0.94 , respectively. In fact, even in the autoclave test, the hydration reaction will not reach $100 \%$ completion. Assuming that the ultimate expansion determined via autoclave tests is close to that under real situations, equation (4) is acceptable for

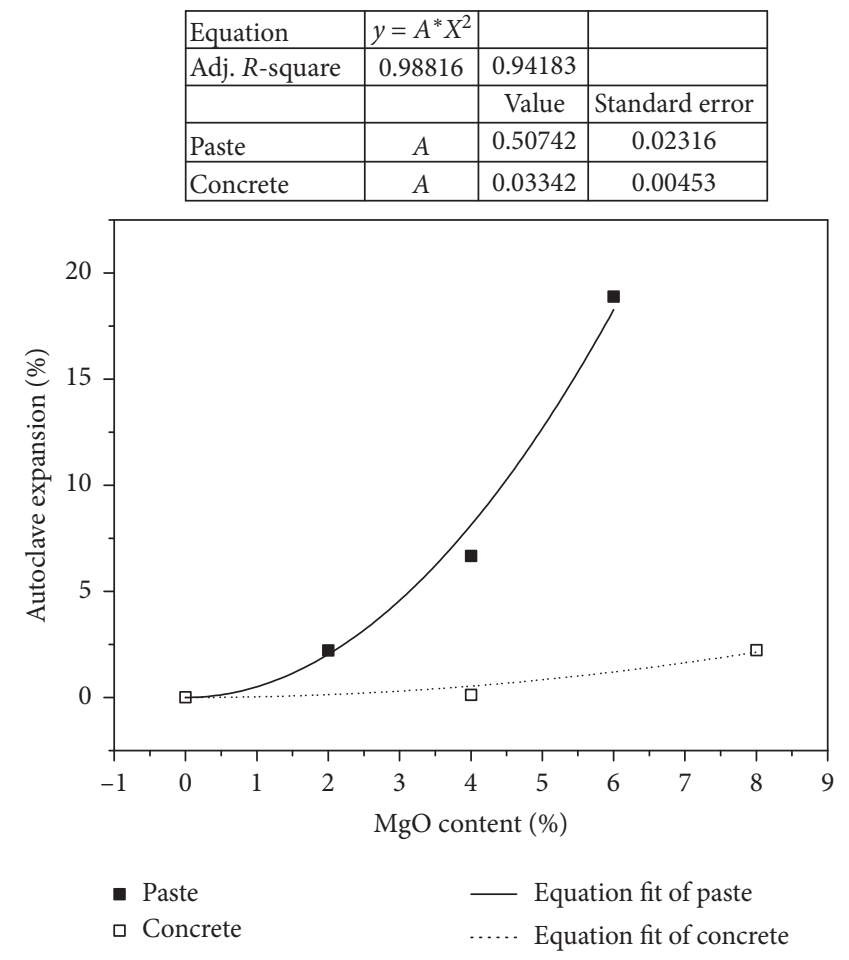

FIgURE 1: Relationship between autoclave expansion and reactive magnesium oxide content.

calculating the ultimate expansion rate while factor $\beta$ is confirmed.

\section{Properties}

4.1. Expansion and Porosity. During the process of $\mathrm{MgO}$ hydration, there are three main stages that may occur at the same time but be dominant at different times. In the first two stages, reactive $\mathrm{MgO}$ particles dissolve and leave pores in the whole system, and then minor $\mathrm{Mg}(\mathrm{OH})_{2}$ crystal grows freely to fill these pores without generating crystal growth pressure. The third stage is dominated by confined crystallization, and expansion is mainly caused by microcracks induced by the crystal growth pressure in the whole system. This stage will increase the pore volume. This assumption that there is an increase in porosity causes the volume of the entire system to increase, as shown in the following equation:

$$
V_{0} p_{0}+V_{0}(1+\varepsilon)^{3}-V_{0}=V_{0}(1+\varepsilon)^{3} p_{e}
$$

where $V_{0}$ is the volume of the system before expansion, $p_{0}$ is the original porosity of the system before expansion, $p_{e}$ is the porosity after expansion, and $\varepsilon$ is the expansion rate after expansion. Porosity $p_{e}$ in equation (5) is determined as follows:

$$
p_{e}=1-\frac{1-p_{0}}{(1+\varepsilon)^{3}}
$$

This equation indicates that expansion will increase the number of pores in the system. According to ASTM C151, the expansion rate limit for maintaining the soundness of 
cement is at $0.8 \%$. Assuming that the original porosity is $10 \%$, after expansion with at a rate of $0.8 \%$, the porosity is $12.12 \%$, as calculated using equation (6). The porosity increase rate after expansion at a rate of $0.8 \%$ is $21.2 \%$. If the expansion rate exceeds $0.8 \%$, the mechanical properties and durability changes caused by porosity should be considered. The relationships between porosity and expansion rate with different original porosities are shown in Figure 2.

4.2. Expansion and Compressive Strength. The fact that a reduction in the porosity of a solid material increases its strength in general and the strength of cement-based materials in particular was recognized long ago [44, 45]. As expansion increases porosity, it should have a role in determining the relationship between the mechanical properties of concrete. Chen et al. [44] evaluated the porosity-strength relationship of cement mortar using the following equation:

$$
\sigma=\sigma_{0}\left[\left(\frac{p_{c}-p}{p_{c}}\right)^{1.85}\left(1-p^{2 / 3}\right)\right]^{1 / 2}
$$

where $\sigma$ is the compressive strength, $\sigma_{0}$ is the compressive strength at zero porosity, $p_{c}$ is the percolation porosity at the failure threshold, and $p$ is the porosity of the system. The application of the theoretical equation to experimental data yields constants $\sigma_{0}$ equal to 69.4 and $p_{c}$ equal to $56.2 \%$ for cement mortar.

While the porosity is $56.2 \%$, the cement matrix disintegrates as shown in Figure 3 and the expansion rate calculated using equation (6) is $21 \%$, assuming the original

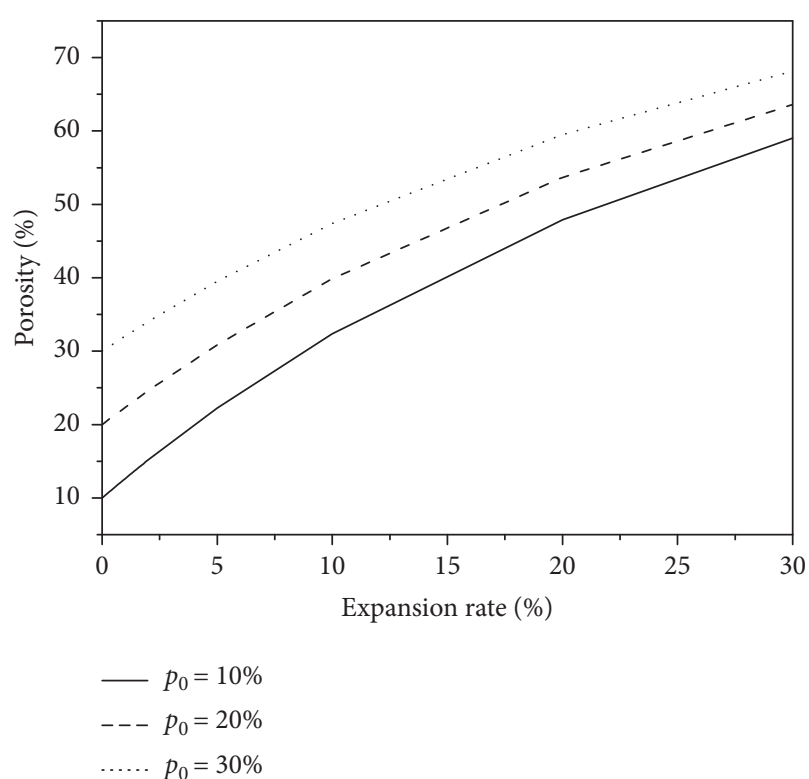

FIGURE 2: Relationships between porosity and expansion rate with different original porosities.

porosity to be $25 \%$ (the mortar compressive strength is $30 \mathrm{MPa}$ with a porosity of $25 \%$ calculated using equation (7)). It is close to the autoclave results obtained in another study [41]; when the expansion rate exceeded $18.89 \%$, the specimen was crushed. By combining equations (6) and (7), the compressive strength of mortar after expansion, $\sigma_{e}$, is given as in the following equation:

$$
\sigma_{e}=\sigma_{0}\left[\left(\frac{p_{c}-\left(1-\left(\left(1-p_{0}\right) /(1+\varepsilon)^{3}\right)\right)}{p_{c}}\right)^{1.85}\left(1-\left(1-\frac{1-p_{0}}{(1+\varepsilon)^{3}}\right)^{2 / 3}\right)\right]^{1 / 2}
$$

Equation (8) shows the relationship between the expansion rate and compressive strength after expansion. An increasing expansion rate will decrease the compressive strength of hydraulic cement systems. This equation does not consider the hydration of cement, which will continue for a long time and will refine the pore structure, decrease the porosity, and then increase the compressive strength on some levels.

4.3. Expansion and Durability. From the viewpoint of the three stages of $\mathrm{MgO}$ hydration discussed above, hydration of $\mathrm{MgO}$ makes the pore structure partially dense or increases the tortuosity of pores, which will improve durability; further, if high expansion occurs, high porosity will reduce durability. Choi et al. investigated the durability properties, including carbonation, freezing-thawing, chloride penetration, and sulfate resistance, of fly ash concrete containing 5\% $\mathrm{MgO}$ by mass of binders as an expansive agent [46]. Experimental results indicated that the compressive strength and durability characteristics of concrete during long-term aging were slightly improved. Gao et al. [47] observed that during the freezing-thawing test performed using the procedure given in ASTM C666, when the content of $\mathrm{MgO}$ expansive agent was increased from $0 \%$ to $4 \%$ and $8 \%$, the strength and mass losses of roller-compacted concrete decreased. When the content of $\mathrm{MgO}$ expansive agent increased from $8 \%$ to $12 \%$, the strength and mass losses of roller-compacted concrete increased. While the $\mathrm{MgO}$ content is relatively low, less than $5 \%$ by mass of binders, most hydration products from the reactive $\mathrm{MgO}$ act as fillers for the concrete pores and increase the tortuosity of pores. Gao et al. [48] also found that fly ash may inhibit the autogenous volume expansion of concrete with $\mathrm{MgO}$ expansive agent, and the effect became more significant on increasing the fly ash content. They concluded that microexpansion caused by $\mathrm{MgO}$ closed the pores of the concrete paste and made the structure denser; this might compensate for the shrinkage of concrete, decrease cracking in concrete works, and improve the durability of concrete. Gonçalves et al. found an overall 


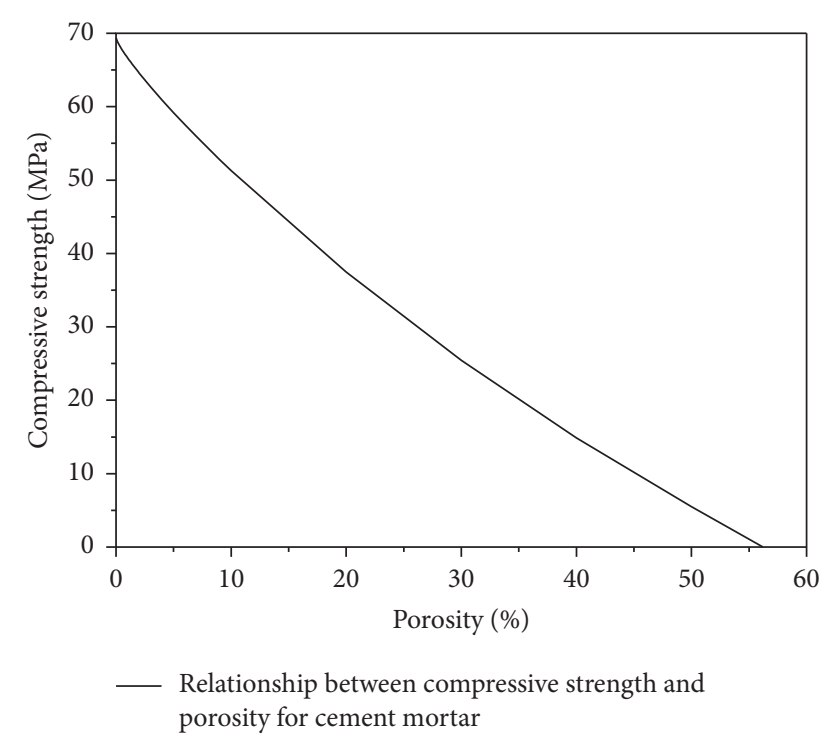

FIGURE 3: Relationship between compressive strength and porosity for cement mortar.

decline in mechanical and durability-related performance with the use of both $\mathrm{MgO}$ and fine recycled concrete aggregates but enhanced shrinkage behaviour was observed in all MgO-containing specimens [49]. Runxiao Zhang and Daman K. Panesar found that reactive magnesium oxide as a replacement of Portland cement not only brings potential to reduce the embodied carbon in construction materials but also brings uncertainties in the volumetric stability of carbonated $\mathrm{MgO}$-Portland cement systems during carbonation curing and sulfate exposure [50].

For shrinkage-compensating concrete or expansive concrete, more expansion is needed to compensate for shrinkage or contraction and the $\mathrm{MgO}$ content should be higher than 5\%. However, it appears that the suitable dosage of $\mathrm{MgO}$ for improving durability is less than 5\%. Further experiments are required to confirm this, and more experiments are needed to study the durability performance of $\mathrm{MgO}$ expansive concrete under combined loadings [51-58].

\section{Expansion via Restraining}

In real concrete structures, expansion of concrete material is always restrained by reinforcements in concrete. On the one hand, a restraining will reduce expansion and decrease porosity when compared with free expansion. Hu and Li [59] studied high-performance expansive fly ash concrete (with an alunite- and gypsum-based expansive agent) and found that confined curing could improve the microstructure of expansive concrete, particularly by intensifying and densifying the paste-aggregate interface. On the other hand, constraining will cause stress, commonly called compressive stress, in concrete materials during the service life of the concrete structure. Wittmman et al. [60] found that application of a moderate compressive stress, a stress up to $35 \%$ of the ultimate stress, decreases the diffusion coefficient of chloride ions in concrete. In summary, expansion under restraining is expected to compact the pore space and close micropores. Likewise, considering the physical process of moisture transport in cement-based materials, which has a direct influence on both service life and durability [61, 62], expansion under constraint retards moisture transportation. Furthermore, for strain-hardening cementitious composite (SHCC) materials, having high strain capacity and resistance against steel rebar corrosion [63, 64], fibers will cause an internal constraint similar to that caused by adding reinforcements. Zhang et al. found that $\mathrm{MgO}$ expansive agents can significantly improve the crack healing efficiency of SHCC under water fog curing conditions [65]. With the designable expansion of $\mathrm{MgO}$ expansive agent, improving the self-healing ability of SHCCs using $\mathrm{MgO}$ expansive hydraulic cement is possible [66]. It is predicted that regulating expansion of cementitious materials with $\mathrm{MgO}$ expansive agent combined with fibers is a novel and promising approach to improve the self-healing ability and durability of SHCCs. In summary, if expansive concrete is restrained, extra compressive stress will be generated and porosity will decrease compared with that during free expansion. Obviously, suitable dosages of $\mathrm{MgO}$ should be determined for use in expansive concrete [67-72].

\section{Conclusions}

(1) Based on the crystallization pressure theory, there are at least three main stages in the hydration of $\mathrm{MgO}$. In the first stage, crystallization occurs when the cement paste or concrete is plastic; in the following stage, crystallization occurs without restraining because the crystal dimensions are relatively small. The above two stages will not cause expansion of the cement system. In the third stage, the cement paste or concrete hardens and crystals are restrained, producing crystallization pressure and thus leading to expansion.

(2) In real concrete structures, hydration of $\mathrm{MgO}$ is an infinite process like the hydration of cement. If the ultimate expansion could be determined, the expansion of $\mathrm{MgO}$ expansive concrete can be predicted approximately at any time using equation (3). Generally, the ultimate expansion rate will increase with the increase in the content of the expansion agent. When the ultimate expansion exceeds some value or the expansion content increases to some value, the whole gel system will disintegrate. The autoclave expansion test is currently the most suitable test for determining the ultimate expansion rate of $\mathrm{MgO}$ expansive hydraulic cement or concrete.

(3) A model for explaining the relationship between the porosity after expansion and expansive rate is presented, along with the equation for calculating the compressive strength of mortar after expansion while considering porosity.

(4) From the viewpoint of the three stages of $\mathrm{MgO}$ hydration, hydration of $\mathrm{MgO}$ will make the pore structure partially dense or increase the tortuosity of the pores, which will improve durability properties; 
however, if high expansion occurs, a high porosity will induce durability properties. If the expansion rate exceeds $0.8 \%$, the mechanical properties and durability changes caused by porosity should be considered. Further experimental studies should be carried out for different types of $\mathrm{MgO}$ expansive agent to verify the expansion mechanism, identify the ultimate expansive rate, and propose suitable $\mathrm{MgO}$ dosage for $\mathrm{MgO}$ expansive hydraulic cement or concrete.

\section{Data Availability}

The data used to support the findings of this study are available from the corresponding author upon request.

\section{Conflicts of Interest}

The authors declare that they have no conflicts of interest regarding the publication of this paper.

\section{Authors' Contributions}

Jinbo Yang conceived and designed the article. Jinbo Yang and Siqi Li analyzed the data. Siqi Li, Yecheng Feng, and Jinbo Yang wrote the paper.

\section{Acknowledgments}

This study was supported by the National Natural Science Foundation of China (51208013).

\section{References}

[1] A. Damgaard Jensen and S. Chatterji, "State of the art report on micro-cracking and lifetime of concrete-part 1," Materials and Structures, vol. 29, no. 1, pp. 3-8, 1996.

[2] ASTM C845-04, Standard Specification for Expansive Hydraulic Cement, ASTM International, West Conshohocken, PA, USA, 2004, http://www.astm.org.

[3] S. Nagataki and H. Gomi, "Expansive admixtures (mainly ettringite)," Cement and Concrete Composites, vol. 20, no. 2-3, pp. 163-170, 1998.

[4] ACI 223, Guide for the Use of Shrinkage-Compensating Concrete, ACI Committee 223R-10, Farmington Hills, MI, USA, 2010.

[5] J. L. García Calvo, D. Revuelta, P. Carballosa, and J. P. Gutiérrez, "Comparison between the performance of expansive SCC and expansive conventional concretes in different expansion and curing conditions," Construction and Building Materials, vol. 136, pp. 277-285, 2017.

[6] P. Gao, X. Lu, F. Geng et al., "Production of MgO-type expansive agent in dam concrete by use of industrial byproducts," Building and Environment, vol. 43, no. 4, pp. 453-457, 2008.

[7] M. Collepardi, R. Troli, M. Bressan, F. Liberatore, and G. Sforza, "Crack-free concrete for outside industrial floors in the absence of wet curing and contraction joints," Cement and Concrete Composites, vol. 30, no. 10, pp. 887-891, 2008.

[8] C. Maltese, C. Pistolesi, A. Lolli, A. Bravo, T. Cerulli, and D. Salvioni, "Combined effect of expansive and shrinkage reducing admixtures to obtain stable and durable mortars,"
Cement and Concrete Research, vol. 35, no. 12, pp. 2244-2251, 2005.

[9] L. Mo, M. Deng, and A. Wang, "Effects of MgO-based expansive additive on compensating the shrinkage of cement paste under non-wet curing conditions," Cement and Concrete Composites, vol. 34, no. 3, pp. 377-383, 2012.

[10] F. Liu, S.-L. Shen, D.-W. Hou, A. Arulrajah, and S. Horpibulsuk, "Enhancing behavior of large volume underground concrete structure using expansive agents," Construction and Building Materials, vol. 114, pp. 49-55, 2016.

[11] M. Ish-Shalom and A. Bentur, "Properties of type $K$ expansive cement of pure components I. hydration of unrestrained paste of expansive component-results," Cement and Concrete Research, vol. 4, no. 4, pp. 519-532, 1974.

[12] A. Bentur and M. Ish-Shalom, "Properties of type K expensive cement of pure components II. proposed mechanism of ettringite formation and expansion in unrestrained paste of pure expansive component," Cement and Concrete Research, vol. 4, no. 5, pp. 709-721, 1974.

[13] M. Ish-Shalom and A. Bentur, "Properties of type $K$ expansive cement of pure components III. hydration of pure expansive component under varying restraining conditions," Cement and Concrete Research, vol. 5, no. 2, pp. 139-152, 1975.

[14] M. Deng and M. Tang, "Formation and expansion of ettringite crystals," Cement and Concrete Research, vol. 24, no. 1, pp. 119-126, 1994.

[15] P. Yan and X. Qin, "The effect of expansive agent and possibility of delayed ettringite formation in shrinkage-compensating massive concrete," Cement and Concrete Research, vol. 31, no. 2, pp. 335-337, 2001.

[16] P. Yan, F. Zheng, J. Peng, and X. Qin, "Relationship between delayed ettringite formation and delayed expansion in massive shrinkage-compensating concrete," Cement and Concrete Composites, vol. 26, no. 6, pp. 687-693, 2004.

[17] L. Mo, M. Deng, M. Tang, and A. Al-Tabbaa, "MgO expansive cement and concrete in China: past, present and future," Cement and Concrete Research, vol. 57, pp. 1-12, 2014.

[18] L. Zheng, C. Mingshu, and M. Tang, "Hydration and setting time of MgO-type expansive cement," Cement and Concrete Research, vol. 22, no. 1, pp. 1-5, 1992.

[19] L. Mo, M. Deng, and M. Tang, "Effects of calcination condition on expansion property of MgO-type expansive agent used in cement-based materials," Cement and Concrete Research, vol. 40, no. 3, pp. 437-446, 2010.

[20] T.-H. Ahn and T. Kishi, "Crack self-healing behavior of cementitious composites incorporating various mineral admixtures," Journal of Advanced Concrete Technology, vol. 8, no. 2, pp. 171-186, 2010.

[21] T. S. Qureshi and A. Al-Tabbaa, "Self-healing of drying shrinkage cracks in cement-based materials incorporating reactive MgO," Smart Materials and Structures, vol. 25, no. 8, Article ID 084004, 2016.

[22] M. A. A. Sherir, K. M. A. Hossain, and M. Lachemi, "Development and recovery of mechanical properties of selfhealing cementitious composites with $\mathrm{MgO}$ expansive agent," Construction and Building Materials, vol. 148, pp. 789-810, 2017.

[23] M. A. A. Sherir, K. M. A. Hossain, and M. Lachemi, "The influence of MgO-type expansive agent incorporated in selfhealing system of Engineered cementitious Composites," Construction and Building Materials, vol. 149, pp. 164-185, 2017.

[24] R. Moradpour, E. Taheri-Nassaj, T. Parhizkar, and M. Ghodsian, "The effects of nanoscale expansive agents on 
the mechanical properties of non-shrink cement-based composites: the influence of nano-MgO addition," Composites Part B: Engineering, vol. 55, pp. 193-202, 2013.

[25] S. Chatterji and J. W. Jeffery, "The volume expansion of hardened cement paste due to the presence of "dead-burnt" CaO," Magazine of Concrete Research, vol. 18, no. 55, pp. 65-68, 1966.

[26] S. Chatterji, "Mechanism of expansion of concrete due to the presence of dead-burnt $\mathrm{CaO}$ and $\mathrm{MgO}$," Cement and Concrete Research, vol. 25, no. 1, pp. 51-56, 1995.

[27] F. Cao, M. Miao, and P. Yan, "Hydration characteristics and expansive mechanism of $\mathrm{MgO}$ expansive agents," Construction and Building Materials, vol. 183, pp. 234-242, 2018.

[28] L. Mo, J. Fang, W. Hou et al., "Synergetic effects of curing temperature and hydration reactivity of $\mathrm{MgO}$ expansive agents on their hydration and expansion behaviours in cement pastes," Construction and Building Materials, vol. 207, pp. 206-217, 2019.

[29] F. Cao and P. Yan, "The influence of the hydration procedure of $\mathrm{MgO}$ expansive agent on the expansive behavior of shrinkage-compensating mortar," Construction and Building Materials, vol. 202, pp. 162-168, 2019.

[30] CBMF 19-2017, Magnesium Oxide Expansive Agent for Concrete, China Building Materials Federation and China Concrete \& Cement-based Products Association, Beijing, China, 2017, in Chinese.

[31] M. Steiger, "Crystal growth in porous materials-I: the crystallization pressure of large crystals," Journal of Crystal Growth, vol. 282, no. 3-4, pp. 455-469, 2005.

[32] M. Steiger, "Crystal growth in porous materials-II: influence of crystal size on the crystallization pressure," Journal of Crystal Growth, vol. 282, no. 3-4, pp. 470-481, 2005.

[33] J. A. Mejias, A. J. Berry, R. Keith, and D. G. Fraser, "The kinetics and mechanism of $\mathrm{MgO}$ dissolution," Chemical Physics Letters, vol. 314, no. 5-6, pp. 558-563, 1999.

[34] D. Filippou, N. Katiforis, N. Papassiopi, and K. Adam, "On the kinetics of magnesia hydration in magnesium acetate solutions," Journal of Chemical Technology \& Biotechnology, vol. 74, no. 4, pp. 322-328, 1999.

[35] V. Kasselouris, C. Ftikos, and G. Parissakis, "On the hydration of $\mathrm{MgO}$ in cement pastes hydrated up to eight years," Cement and Concrete Research, vol. 15, no. 5, pp. 758-764, 1985.

[36] A. J. Majumdar and S. S. Rehsi, "The mechanism of stabilization of highmagnesia Portland cements by reactive silica under autoclave conditions," Magazine of Concrete Research, vol. 21, no. 68, pp. 141-150, 1969.

[37] M. Yuan, "Study on deformation characteristics of micro expansion concrete of MgO-admixed," pp. 81-109, Wuhan University, Wuhan, China, 2013, Ph. D. dissertation.

[38] R. Wang, Q. Tian, S. Zhang et al., "Improving efficiency of calcium oxide expansive additives by polylactic acid film," Magazine of Concrete Research, vol. 68, no. 20, pp. 1070-1078, 2016.

[39] ASTM C151/C151M-18, Standard Test Method for Autoclave Expansion of Hydraulic Cement, ASTM International, West Conshohocken, PA, USA, 2018, http://www.astm.org.

[40] R. Helmuth and P. B. West, "Reappraisal of the autoclave expansion test," Cement, Concrete and Aggregates, vol. 20, no. 1, pp. 194-219, 1998.

[41] R. Michelle, "Nokken, Expansion of MgO in cement pastes measured by different methods," ACI Materials Journal, vol. 107, no. 1, pp. 80-84, 2010.
[42] L. Mo, M. Deng, and M. Tang, "Potential approach to evaluating soundness of concrete containing MgO-based expansive agent," ACI Materials Journal, vol. 107, no. 2, pp. 99-105, 2010.

[43] P.-w. Gao, S.-x. Wu, X.-l. Lu et al., "Soundness evaluation of concrete with $\mathrm{MgO}$," Construction and Building Materials, vol. 21, no. 1, pp. 132-138, 2007.

[44] X. Chen, S. Wu, and J. Zhou, "Influence of porosity on compressive and tensile strength of cement mortar," Construction and Building Materials, vol. 40, pp. 869-874, 2013.

[45] R. Kumar and B. Bhattacharjee, "Porosity, pore size distribution and in situ strength of concrete," Cement and Concrete Research, vol. 33, no. 1, pp. 155-164, 2003.

[46] S.-w. Choi, B.-s. Jang, J.-h. Kim, and K.-m. Lee, "Durability characteristics of fly ash concrete containing lightly-burnt MgO," Construction and Building Materials, vol. 58, pp. 7784, 2014.

[47] P.-w. Gao, S.-x. Wu, P.-h. Lin, Z.-r. Wu, and M.-s. Tang, "The characteristics of air void and frost resistance of RCC with fly ash and expansive agent," Construction and Building Materials, vol. 20, no. 8, pp. 586-590, 2006.

[48] P.-w. Gao, S.-y. Xu, X. Chen, J. Li, and X.-1. Lu, "Research on autogenous volume deformation of concrete with $\mathrm{MgO}$," Construction and Building Materials, vol. 40, pp. 998-1001, 2013.

[49] T. Gonçalves, R. V. Silva, J. de Brito, J. M. Fernández, and A. R. Esquinas, "Mechanical and durability performance of mortars with fine recycled concrete aggregates and reactive magnesium oxide as partial cement replacement," Cement and Concrete Composites, vol. 105, Article ID 103420, 2020.

[50] R. Zhang and K. P. Daman, "Longitudinal deformation of mortar bars containing reactive $\mathrm{MgO}$ during carbonation curing and sulfate solution immersion," Journal of Materials in Civil Engineering, vol. 31, no. 11, Article ID 04019275, 2019.

[51] P. Zhang, F. H. Wittmann, M. Vogel, H. S. Müller, and T. Zhao, "Influence of freeze-thaw cycles on capillary absorption and chloride penetration into concrete," Cement and Concrete Research, vol. 100, no. 10, pp. 60-67, 2017.

[52] P. Zhang, D. Li, Y. Qiao, S. Zhang, C. T. Sun, and T. Zhao, "The effect of air entrainment on the mechanical properties, chloride migration and microstructure of ordinary concrete and fly ash concrete," ASCE Journal of Materials in Civil Engineering, vol. 30, no. 10, Article ID 04018265, 2018.

[53] Y. Wang, Y. Cao, P. Zhang et al., "Water absorption and chloride diffusivity of concrete under the coupling effect of uniaxial compressive load and freeze-thaw cycles," Construction and Building Materials, vol. 209, pp. 566-576, 2019.

[54] Q. Song, H. Zhao, J. Jia et al., "Pyrolysis of municipal solid waste with iron-based additives: a study on the kinetic, product distribution and catalytic mechanisms," Journal of Cleaner Production, vol. 258, Article ID 120682, 2020.

[55] Y. Tian, P. Zhang, K. Zhao, Z. Du, and T. Zhao, "Application of $\mathrm{Ag} / \mathrm{AgCl}$ sensor for chloride monitoring of mortar under dry-wet cycles," Sensors, vol. 20, no. 5, p. 1394, 2020.

[56] J. W. Bao, S. B. Xue, P. Zhang, Z. Dai, and Y. F. Cui, "Coupled effects of sustained compressive loading and freeze-thaw cycles on water penetration into concrete," Structural Concrete, vol. 22, no. S1, 2020.

[57] K. Zhao, Y. Qiao, P. Zhang, J. Bao, and Y. Tian, "Experimental and numerical study on chloride transport in cement mortar during drying process," Construction and Building Materials, vol. 258, Article ID 119655, 2020.

[58] J. Bao, S. Li, P. Zhang et al., "Influence of the incorporation of recycled coarse aggregate on water absorption and chloride 
penetration into concrete," Construction and Building Materials, vol. 239, Article ID 117845, 2020.

[59] S. Hu and $\mathrm{Y}$. Li, "Research on the hydration, hardening mechanism, and microstructure of high performance expansive concrete," Cement and Concrete Research, vol. 29, no. 7, pp. 1013-1017, 1999.

[60] F. H. Wittmann, F. Jiang, T. Zhao, and Y. Wang, "Influence of an applied compressive stress on service life of reinforced concrete structures in marine environment," Restoration of Buildings and Monuments, vol. 19, no. 1, pp. 3-10, 2013.

[61] P. Zhang, F. H. Wittmann, P. Lura, H. S. Müller, S. Han, and T. Zhao, "Application of neutron imaging to investigate fundamental aspects of durability of cement-based materials: a review," Cement and Concrete Research, vol. 108, pp. 152166, 2018.

[62] S. Xue, P. Zhang, J. Bao, L. He, Y. Hu, and S. Yang, "Comparison of mercury intrusion porosimetry and multi-scale X-ray CT on characterizing the microstructure of heat-treated cement mortar," Materials Characterization, vol. 160, Article ID 110085, 2020.

[63] P. Zhang, P. Wang, D. Hou, Z. Liu, M. Haist, and T. Zhao, "Application of neutron radiography in observing and quantifying the time-dependent moisture distributions in multi-cracked cement-based composites," Cement and Concrete Composites, vol. 78, pp. 13-20, 2017.

[64] P. Zhang, Z. Liu, Y. Wang, J. Yang, S. Han, and T. Zhao, “3D neutron tomography of steel reinforcement corrosion in cement-based composites," Construction and Building Materials, vol. 162, pp. 561-565, 2018.

[65] P. Zhang, Y. Dai, W. Wang et al., "Effects of magnesia expansive agents on the self-healing performance of microcracks in strain-hardening cement-based composites (SHCC)," Materials Today Communications, vol. 25, Article ID 101421, 2020.

[66] H. Wu, J. Yu, Y. Du, and V. C. Li, "Mechanical performance of MgO-doped engineered cementitious composites (ECC)," Cement and Concrete Composites, vol. 115, Article ID 103857, 2021.

[67] F. Jiang, Z. Mao, M. Deng, and D. Li, "Deformation and compressive strength of steel fiber reinforced MgO concrete," Materials, vol. 12, no. 21, p. 3617, 2019.

[68] H. Kabir and R. D. Hooton, "Evaluating soundness of concrete containing shrinkage-compensating MgO admixtures," Construction and Building Materials, vol. 253, Article ID 119141, 2020.

[69] H. Kabir, R. D. Hooton, and N. J. Popoff, "Evaluation of cement soundness using the ASTM C151 autoclave expansion test," Cement and Concrete Research, vol. 136, Article ID 106159, 2020.

[70] J. Guo, T. Guo, S. Zhang, and Y. Lu, "Experimental study on freezing and thawing cycles of shrinkage-compensating concrete with double expansive agents," Materials, vol. 13, no. 8, p. 1850, 2020.

[71] R. Hay and K. Celik, "Hydration, carbonation, strength development and corrosion resistance of reactive $\mathrm{MgO}$ cementbased composites," Cement and Concrete Research, vol. 128, Article ID 105941, 2020.

[72] S. Li, S. Cheng, L. Mo, and M. Deng, "Effects of steel slag powder and expansive agent on the properties of ultra-high performance concrete (UHPC): based on a case study," Materials, vol. 13, no. 3, p. 683, 2020. 